\title{
Editorial
}

\section{Anthropogenic Pollution at both Sides of the Strait of Gibraltar}

\section{Carlos Moreno*}

Department of Analytical Chemistry, Faculty of Marine and Environmental Sciences, University of Cádiz, 11510 Puerto Real, Spain

The Strait of Gibraltar is a narrow strip of water which is the only connection of the Mediterranean Sea with the Atlantic Ocean. Located between Spain and Morocco, it is a strategical area from many points of view points, e.g. political, socio-economical, ecological, etc.

Due to the pressure of human impact, it is undergoing an alteration in its environmental quality, mainly caused by the heavy concentration of shipping traffic and anthropogenic pollution originated at both sides of the strait.

The acceptance by authorities of this quality deterioration if the strait, as well as its role as a natural barrier crossed by migrants from the south to the north, has made easier the implementation of supranational cooperation programs, some of which allowed to carry out different research projects to evaluate the pollution of, among others, a variety of ecosystems that may be affected by human activities. Besides, some of these projects provided an excellent framework to establish solid scientific relationships between European Research Groups and the corresponding colleagues from emerging countries from Northern Africa.

In this context, this Special Issue of The Open Journal of Environmental Pollution and Toxicology Journal focuses on several experimental studies developed in the area of the Strait of Gibraltar by both African and European researchers to establish different aspects of the pollution of this zone. It provides novelty, knowledge and quite interesting data about an important but poorly studied geographical zone, that will be important by itself, and very specially to be used by other scientist in future studies.

*Address correspondence to this author at the Department of Analytical Chemistry, Faculty of Marine and Environmental Sciences, University of Cádiz, 11510 Puerto Real, Spain; E-mail: carlos.moreno@uca.es

(C) Carlos Moreno; Licensee Bentham Open.

This is an open access article licensed under the terms of the Creative Commons Attribution Non-Commercial License (http://creativecommons.org/licenses/by$\mathrm{nc} / 3.0 /$ ), which permits unrestricted, non-commercial use, distribution and reproduction in any medium, provided the work is properly cited. 